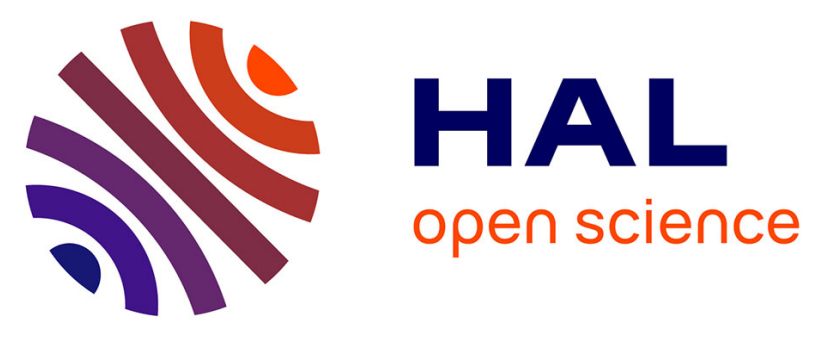

\title{
Direct Observation of Short-Range Structural Coherence During a Charge Transfer Induced Spin Transition in a CoFe Prussian Blue Analogue by Transmission Electron Microscopy
}

Miho Itoi, Toyoharu Jike, Daisuke Nishio-Hamane, Seiichi Udagawa, Tetsuya Tsuda, Susumu Kuwabata, Kamel Boukheddaden, Matthew Andrus, Daniel Talham

\section{- To cite this version:}

Miho Itoi, Toyoharu Jike, Daisuke Nishio-Hamane, Seiichi Udagawa, Tetsuya Tsuda, et al.. Direct Observation of Short-Range Structural Coherence During a Charge Transfer Induced Spin Transition in a CoFe Prussian Blue Analogue by Transmission Electron Microscopy. Journal of the American Chemical Society, 2015, 137 (46), pp.14686-14693. 10.1021/jacs.5b08242 · hal-03001197

\author{
HAL Id: hal-03001197 \\ https://hal.science/hal-03001197
}

Submitted on 6 Dec 2021

HAL is a multi-disciplinary open access archive for the deposit and dissemination of scientific research documents, whether they are published or not. The documents may come from teaching and research institutions in France or abroad, or from public or private research centers.
L'archive ouverte pluridisciplinaire HAL, est destinée au dépôt et à la diffusion de documents scientifiques de niveau recherche, publiés ou non, émanant des établissements d'enseignement et de recherche français ou étrangers, des laboratoires publics ou privés.

\section{(ㄷ)(1) $\$$}

Distributed under a Creative Commons Attribution - NonCommerciall 4.0 International 


\title{
Direct Observation of Short-Range Structural Coherence Dur- ing a Charge Transfer Induced Spin Transition in a CoFe Prussian Blue Analogue by Transmission Electron Microsco- py.
}

Miho Itoi ${ }^{1 *}$, Toyoharu Jike ${ }^{1}$, Daisuke Nishio-Hamane ${ }^{2}$, Seiichi Udagawa ${ }^{1}$, Tetsuya Tsuda ${ }^{3}$, Susumu Kuwabata ${ }^{3}$, Kamel Boukheddaden ${ }^{4}$, Matthew J. Andrus ${ }^{5}$ and Daniel R Talham ${ }^{5,{ }^{*}}$

${ }^{1}$ Division of Physics, Institute of Liberal Education, Nihon University School of Medicine, Tokyo 173-8610, Japan

${ }^{2}$ Institute for Solid State Physics, The University of Tokyo, Chiba 277-8581, Japan

${ }^{3}$ Department of Applied Chemistry, Graduate School of Engineering, Osaka University, Suita, Osaka 565-o871, Japan

${ }^{4}$ Groupe d'Etudes de la Matière Condensée, UMR 8635, CNRS-Université de Versailles Saint-Quentin-en-Yvelines, 45 Avenue des Etats Unis, 78035 Versailles, France

${ }^{5}$ Department of Chemistry, University of Florida, P.O. Box 117200, Gainesville, FL 32611-7200

KEYWORDS. Photo-switchable molecular magnet, TEM measurement, Local lattice structure, ionic liquid

\begin{abstract}
The local structure within the Co-Fe atomic array of the photo-switchable coordination polymer magnet, $\mathrm{K}_{\mathrm{o} .3} \mathrm{Co}\left[\mathrm{Fe}(\mathrm{CN})_{6}\right]_{0.77} \cdot n \mathrm{H}_{2} \mathrm{O}$, is directly observed during charge transfer induced spin transition (CTIST), a solid-solid phase change, using high resolution transmission electron microscopy (HRTEM). Along with the low-spin (LS) or thermally quenched high-spin (HS) states normally observed in CTIST solids at low temperature, slow cooling of $\mathrm{K}_{0.3} \mathrm{Co}\left[\mathrm{Fe}(\mathrm{CN})_{6}\right]_{0.77} \cdot n \mathrm{H}_{2} \mathrm{O}$, results in an intermediate phase containing both HS and LS domains with short coherence length. By mapping individual metal-metal distances, the nanometer scale HS domains are directly visualized within the LS array. Temperature dependent analyses allow monitoring of HS domain-coarsening along the warming branch of the CTIST, providing direct visualization of the elastic process and insight into the mechanism of phase propagation. Normally sensitive to electron beam damage, the low temperature TEM measurements of the porous coordination polymer are enabled by using appropriate ionic liquids instead of usual conductive thin film coatings, an approach that should find general utility in related classes of materials.
\end{abstract}




\section{INTRODUCTION}

Direct observation of local atomic structure is expected to give deep insights into how short-range interactions and mesoscale cooperative effects relate to macroscopic responses in materials. Metal-organic coordination polymer materials present a special case as their elastic lattice structure is strongly coupled to their functional properties such as sorption, ion storage, catalysis, magnetism and external-field switchable magnetism. ${ }^{1}$ In parallel, functional coordination polymer or metal organic framework heterostructures such as nanocomposites, core-shell particles or thin films have been developed in recent years for which interfacial structural characteristics influence physical properties. ${ }^{2}$ Atomic level investigations will be critical for full understanding of how macroscopic behavior relates to local structure, local lattice dynamics and phonon propagation in these mesoscale materials. The present study uses highresolution transmission electron microscopy (TEM) to directly monitor the distribution of interatomic distances during a structural phase transition in a coordination polymer solid, gaining insight into the elastic distribution of the different phases. The study is enabled by coating the coordination polymer particles with an ionic liquid (IL) in the TEM, stabilizing the porous solids against normally observed degradation under high-vacuum conditions.

Prussian blue analogues (PBAs) are prototypical porous coordination polymer solids, which have attracted considerable recent attention in studies of alkali ion storage, ${ }^{3}$ negative thermal expansion and photoswitchable molecular magnetism., ${ }^{4,5}$ The family of cobalt hexacyanoferrates (CoFe-PBAs), Scheme 1, is wellknown for light-switchable magnetism, whereby a charge transfer induced spin transition (CTIST) between the $\mathrm{Fe}^{\mathrm{III}} \mathrm{LS}-\mathrm{CN}-\mathrm{Co}^{\mathrm{II}} \mathrm{HS}$ (referred to here as the high-spin or HS state) and Fe ${ }^{\text {II }} \mathrm{LS},-\mathrm{CN}-\mathrm{Co}^{\mathrm{III}} \mathrm{LS}$ (low-spin or LS state) states alters magnetization. The CTIST is also associated with a large structural transformation resulting from the change in $\mathrm{Co}-\mathrm{N}$ bond distance in the two spin states. ${ }^{6,7}$ The states can be interconverted thermally, between the high-temperature HS state and low-temperature LS state, or optically from the LS state to a metastable HS state below a characteristic relaxation temperature. The high-spin CoFe-PBAs magnetically order at low temperature, so they represent still rare examples of light-switchable magnets. ${ }^{6}$

The CTIST in the CoFe-PBAs is strongly coupled to the lattice, so details of the transition depend on composition, including the choice of counterion and extent of cyanometallate vacancies. For the present study, we have chosen to investigate the unusual behavior of the non-stoichiometric analogue $\mathrm{K}_{0.3} \mathrm{Co}\left[\mathrm{Fe}(\mathrm{CN})_{6}\right]_{0.77} \cdot n \mathrm{H}_{2} \mathrm{O}$, which has been shown to exhibit multistability with three inter-convertible states at low temperatures: a quenched high-spin state $(\mathrm{Q})$ reached by rapid cooling, a low-spin state (LT) accessed by the thermal decay of the Q state, and an intermediate state (IM) achieved by slow cooling from room temperature (Figure 1). ${ }^{8}$ The $\mathrm{Q}$ and IM states magnetically order (Figure $\mathrm{S}_{1}$ and Table $\mathrm{S} 1) .{ }^{8(\mathrm{~b})}$ In the IM state, HS and LS fractions coexist due to an elastic stress associated with the large volume change of the CTIST. ${ }^{9}$ It has been shown that particle size influences the appearance of the IM state, although the relationship between HS and LS fractions within the lattice is still unclear. ${ }^{10}$ Quantitative information on the elastic stress in the crystal during the IM state selforganization process will help to understand its appearance, as well as the conditions for stabilizing the Q state or LT state.

The TEM described here is shown to give directly spatial information of the local microstructures at the atomic level. Although normally sensitive to the conditions of the TEM experiment, use of an appropriate ionic liquid is shown to lead to stable atomic level TEM observations of the iron and cobalt atomic array during the CTIST for $\mathrm{K}_{0.3} \mathrm{Co}\left[\mathrm{Fe}(\mathrm{CN})_{6}\right]_{0.77} \cdot n \mathrm{H}_{2} \mathrm{O}$ mesoscale particles. Direct observation of HS domain coarsening during the thermal LS $\rightarrow$ HS transition gives insight into the short structural coherence caused by the CTIST in the IM state and the elastic structure of the sample.

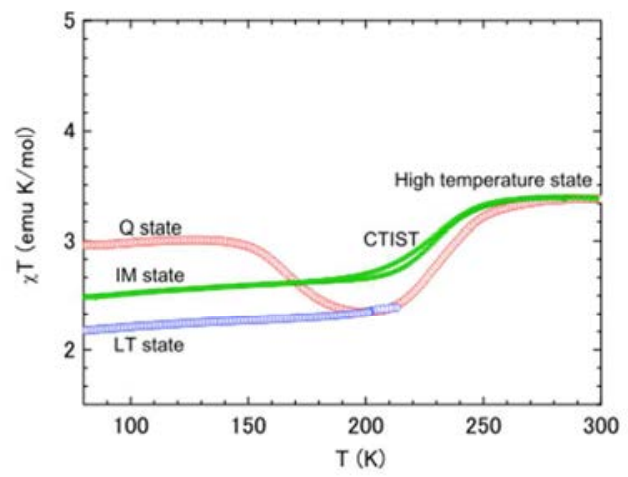

Figure 1. Temperature dependent magnetic susceptibility of $\mathrm{K}_{\mathrm{o} .3} \mathrm{Co}\left[\mathrm{Fe}(\mathrm{CN})_{6}\right]_{0.77} \mathrm{nH}_{2} \mathrm{O}$ between 80 and $300 \mathrm{~K}$. The mean particle size in the sample is approximately $135 \mathrm{~nm}$. The quenched $(\mathrm{Q})$ state, which has the $\mathrm{Co}^{\mathrm{II}}(\mathrm{S}=3 / 2)-\mathrm{Fe}^{\mathrm{III}}(\mathrm{S}=1 / 2)$, or HS state, is obtained by rapid cooling from room temperature to $10 \mathrm{~K}$. The low temperature $\mathrm{Co}^{\mathrm{III}}(\mathrm{S}=\mathrm{o})-\mathrm{Fe}^{\mathrm{II}}(\mathrm{S}=\mathrm{O})$, or LS state, is achieved from thermal control of the Q state. The IM state is obtained by slow cooling $(1 \mathrm{~K} / \mathrm{min})$ from room temperature. The data and assignments are consistent with previous reports. ${ }^{8 \mathrm{a}, \mathrm{lo}}$

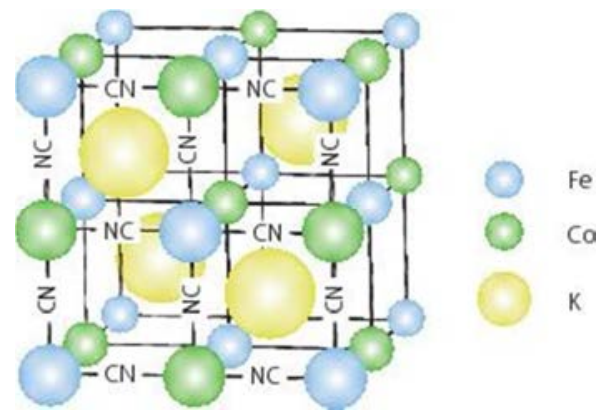

Scheme 1. The parent CoFe-PBA structure, $\mathrm{KCo}\left[\mathrm{Fe}(\mathrm{CN})_{6}\right]$. The Co-NC-Fe frame makes a ${ }_{3} \mathrm{D}$ cubic structure with counterions in the tetrahedral sites. In the case of title compound, $\mathrm{K}_{\mathrm{o} .3} \mathrm{Co}\left[\mathrm{Fe}(\mathrm{CN})_{6}\right]_{0.77} \cdot n \mathrm{H}_{2} \mathrm{O}, 0.23$ of the $\left[\mathrm{Fe}(\mathrm{CN})_{6}\right]$ octahedral sites are vacant and replaced by coordinating water molecules and the occupancy of the $\mathrm{K}$ atoms (wycoff site 8 of the Fmzm space group) is 0.3 . 


\section{EXPERIMENTAL SECTION}

The $\mathrm{K}_{0.3} \mathrm{Co}\left[\mathrm{Fe}(\mathrm{CN})_{6}\right]_{0.77} \cdot n \mathrm{H}_{2} \mathrm{O}$ particles with average size of $135 \mathrm{~nm}$ (Figure $\mathrm{S}_{2}$ ) were prepared as described in previous papers. ${ }^{8(a), 10}$ Transmission electron microscopy (TEM) was performed with JEM-210o and JEM-2010F microscopes (JEOL), using a voltage of $200 \mathrm{kV}$ at the Institute for Solid State Physics of The University of Tokyo. Images were recorded with an imaging plate detector and CCD camera. The ionic liquids, for example $\left[\left(\mathrm{CH}_{3}\right)_{3} \mathrm{NC}_{2} \mathrm{H}_{4} \mathrm{OH}\right]\left[\mathrm{CH}_{3} \mathrm{C}(\mathrm{OH}) \mathrm{CO}_{2}\right]$ (choline lactate:[Ch][Lac]), were diluted with water to $1 \mathrm{vol} \%$ of IL/water with ultrasonic agitation. The ionic liquid was micro-pipetted onto the $\mathrm{K}_{0.3} \mathrm{Co}\left[\mathrm{Fe}(\mathrm{CN})_{6}\right]_{0.77} \cdot n \mathrm{H}_{2} \mathrm{O}$ particles on $\mathrm{Cu}$-conductive mesh grids (Nisshin EM). The grids were placed in an oven at $60^{\circ}$ Celsius for $\sim 15 \mathrm{~min}$ to remove water from the IL droplet. Low temperature TEM observations used a liquid He cooled specimen holder (JEOL). Stable TEM measurement could be carried out in the temperature range from $\sim 210 \mathrm{~K}$ to $300 \mathrm{~K}$. TEM image analysis was performed with free software Image $^{\mathrm{II}}$ for fast Fourier transformations and with an original imaging program written for Matlab for atomic position calculations.

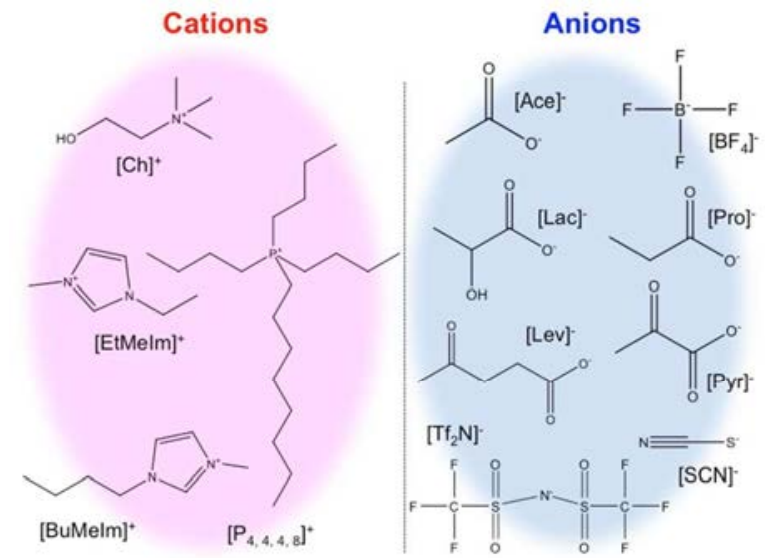

Scheme 2. Cations and anions of the ionic liquids used in this study.

\section{RESULTS\&DISCUSSION}

\section{Ionic liquids for TEM analysis of CoFe-PBA parti-} cles.

Transmission electron microscopy is used to observe microscopic and/or geometric structures for elastic strain evaluation in semiconductor device and nanoparticles. ${ }^{12}$ However, electron irradiation causes heating, electrostatic charging or ionization damage often making the measurement difficult. ${ }^{13}$ Metal-organic coordination polymer solids like the CoFe-PBAs are especially susceptible to electron beam damage, even at very short exposure times. We have succeeded in achieving stable temperature-dependent TEM observations in $\mathrm{K}_{0.3} \mathrm{Co}\left[\mathrm{Fe}(\mathrm{CN})_{6}\right]_{0.77} \cdot n \mathrm{H}_{2} \mathrm{O}$ by wetting the particles with an ionic liquid. The IL prevents the sample from melting or bursting when interacting with the electron beam. Also, compared to typical carbon or $\mathrm{PtPb}$ thin film coatings, sample charging is reduced, leading to sharper and clearer TEM images.

Ionic liquids (Scheme 2) are widely studied and have found significant use in materials synthesis and analysis. ${ }^{14}$ Since ILs have negligible vapor pressure, they can be used for analysis under vacuum conditions. Furthermore, as ILs are ionic conductors, they can protect samples from charging and heating during SEM and TEM measurements. They have found use in SEM or TEM observations of biological samples that can be fragile under high-vacuum or heavily distorted if dried. ${ }^{15}$ ILs have also been recently applied for in situ TEM analysis of the growth mechanism of gold nanoparticles. ${ }^{16}$ However, as far as we are aware, this is the first time ILs have been used to stabilize coordination polymer solids for electron microscopy.

Several IL systems were explored to find suitable conditions for imaging the CoFe-PBA, including seven types of hydrophilic ionic liquids, two types of hydrophobic ionic liquids, as well as combinations with different additives (table 1). The identity and dilution ratio of the IL proved to be important parameters for clear TEM observation. Choline lactate and choline pyruvate were found to be effective ILs for the KCoFe-PBA particles that were studied. It is likely that the nature of surface absorption plays a role in the effectiveness of the IL. The range of conditions that were explored and those found to be most effective are described in Table I.
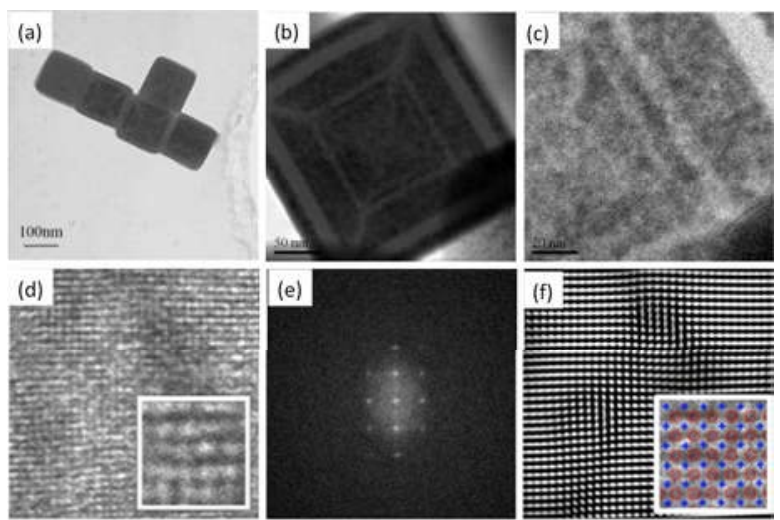

Figure 2. TEM images of $\mathrm{K}_{0.3} \mathrm{Co}\left[\mathrm{Fe}(\mathrm{CN})_{6}\right]_{0.77} \cdot n \mathrm{H}_{2} \mathrm{O}$ using the ionic liquid, $\left[\left(\mathrm{CH}_{3}\right)_{3} \mathrm{NC}_{2} \mathrm{H}_{4} \mathrm{OH}\right]\left[\mathrm{CH}_{3} \mathrm{C}(\mathrm{OH}) \mathrm{CO}_{2}\right]$ ([Ch][Lac], 1 vol\%). (a) The average particle size of $\mathrm{K}_{0.3} \mathrm{Co}\left[\mathrm{Fe}(\mathrm{CN})_{6}\right]_{0.77} n \mathrm{H}_{2} \mathrm{O}$ is about $\sim 135 \mathrm{~nm}$. (b),(c) larger particles of $\mathrm{K}_{0.3} \mathrm{Co}\left[\mathrm{Fe}(\mathrm{CN})_{6}\right]_{0.77} n \mathrm{H}_{2} \mathrm{O}$ at two magnifications at room temperature. (d) An HRTEM image at $286 \mathrm{~K}$ with $1500 \mathrm{k}$ magnification. A coherent checked pattern related to the alternating Co-Fe array is observed. (e) The reciprocal image of frame d obtained by Fourier transformation. (f) The periodic structure is extracted by Fourier filtering from e. (Inset) A partial image of $\mathrm{d}$ with the $\mathrm{Co}$ and $\mathrm{Fe}$ atomic positions, dark spots in the TEM, indicated with red circles and the centers of Co-Fe cubic lattices, the empty suboctants corresponding to the wycoff site 8 of the Fm3m space group, indicated by the blue crosses. 
Table I. Analysis of the efficiency of different ionic liquids for TEM measurements of KCoFe-PBA at room temperature.

\begin{tabular}{|c|c|c|c|}
\hline Category & Name & $\begin{array}{l}\text { Definitive dilution } \\
\text { ratio }\end{array}$ & $\begin{array}{l}\text { Observation } \\
\text { stability at } \\
300 \mathrm{~K} \\
\text { (Efficiency) }^{\mathrm{a}}\end{array}$ \\
\hline \multirow[t]{19}{*}{$\begin{array}{l}\text { Hydrophilic Ionic } \\
\text { Liquid }\end{array}$} & 1 Choline lactate $\left[\left(\mathrm{CH}_{3}\right)_{3} \mathrm{NC}_{2} \mathrm{H}_{2} \mathrm{OH}\right]\left[\mathrm{CH}_{3} \mathrm{C}(\mathrm{OH}) \mathrm{CO}_{2}\right]$ & 1:100 (with $\mathrm{H}_{2} \mathrm{O}$ ) & (-) \\
\hline & 2 & 1:50 (with $\mathrm{H}_{2} \mathrm{O}$ ) & (-) \\
\hline & 3 plus $10 \% \mathrm{vol} \mathrm{H}_{2} \mathrm{O}+$ choline dihydrogen phosphate & 1:10 (with $\mathrm{H}_{2} \mathrm{O}$ ) & $\Delta$ \\
\hline & 4 plus $50 \%$ vol $\mathrm{H}_{2} \mathrm{O}+$ samarium sulfate & 1:10 (with $\mathrm{H}_{2} \mathrm{O}$ ) & $\times$ \\
\hline & 5 plus $50 \%$ vol $\mathrm{H}_{2} \mathrm{O}+$ sodium chloride & 1:10 (with $\mathrm{H}_{2} \mathrm{O}$ ) & $\circ$ \\
\hline & 6 plus $50 \%$ vol $\mathrm{H}_{2} \mathrm{O}+$ choline dihydrogen phosphate & 1:10 (with $\mathrm{H}_{2} \mathrm{O}$ ) & $\times$ \\
\hline & plus $10 \%$ vol $\mathrm{H}_{2} \mathrm{O}+\mathrm{Pt}$ nanoparticle & 1:10 (with $\mathrm{H}_{2} \mathrm{O}$ ) & $\Delta$ \\
\hline & 8 Choline propionate & 1:100 (with $\mathrm{H}_{2} \mathrm{O}$ ) & $\Delta$ \\
\hline & 9 & 1:20 (with $\mathrm{H}_{2} \mathrm{O}$ ) & ○ \\
\hline & 10 Choline levulinate & 1:100 (with $\mathrm{H}_{2} \mathrm{O}$ ) & $\times$ \\
\hline & 11 & 1:20 (with $\mathrm{H}_{2} \mathrm{O}$ ) & $\triangle$ \\
\hline & 12 Choline pyruvate & 1:100 (with $\mathrm{H}_{2} \mathrm{O}$ ) & $\triangle$ \\
\hline & 13 & 1:20 (with $\mathrm{H}_{2} \mathrm{O}$ ) & (-) \\
\hline & $\begin{array}{l}\mathbf{1 4}[\text { BuMeIm }]\left[\mathrm{BF}_{4}\right] \quad([1-\text { butyl-3- } \\
\text { methylimizolium][tetrafluoroborate }])\end{array}$ & 1:5 (with $\mathrm{H}_{2} \mathrm{O}$ ) & $\Delta$ \\
\hline & 15 & 1:10 (with $\mathrm{H}_{2} \mathrm{O}$ ) & $\times$ \\
\hline & 16 [EtMeIm][Ace] & 1:100 (with $\mathrm{H}_{2} \mathrm{O}$ ) & ○ \\
\hline & 17 & 1:20 (with $\mathrm{H}_{2} \mathrm{O}$ ) & ○ \\
\hline & $18[$ EtMeIm] $[\mathrm{Lac}]$ & 1:100 (with $\mathrm{H}_{2} \mathrm{O}$ ) & $\Delta$ \\
\hline & 19 & 1:20 (with $\mathrm{H}_{2} \mathrm{O}$ ) & $\triangle$ \\
\hline \multirow{2}{*}{$\begin{array}{c}\text { Hydrophobic Ionic } \\
\text { Liquid }\end{array}$} & 20 Tributyloctylphoshpnium thiocyanate $[\mathrm{P} 4,4,48][\mathrm{SCN}]$ & $\begin{array}{l}\text { Undiluted solu- } \\
\text { tion }\end{array}$ & $\Delta$ \\
\hline & $\begin{array}{l}21 \text { Tributyloctylphoshpnium bis(trifluoromethanesulfonyl) } \\
\text { amide }[\mathrm{P} 4,4,48][\mathrm{Tf} 2 \mathrm{~N}]\end{array}$ & $\begin{array}{l}\text { Undiluted solu- } \\
\text { tion }\end{array}$ & $\circ$ \\
\hline Without IL & 22 Carbon vapor deposition & - & $\Delta$ \\
\hline \multicolumn{4}{|c|}{$\begin{array}{l}\text { a. The effectiveness is qualitatively evaluated using 4-levels of stability under } 120 \mathrm{kV} / 100 \mathrm{k} \text { magnification continuous obser- } \\
\text { vation; } \times \text { : sample damaged within } 1 \text { minute or unstable/poor image visibility, } \Delta \text { : stable for } 2 \text { minutes, } \bigcirc \text { : stable for } \sim 3 \\
\text { minutes with clear image visibility }(\bigcirc \text { : stable more than } 4 \text { minutes and clear image visibility. }\end{array}$} \\
\hline
\end{tabular}


Particle imaging and local spin-state analysis.

\section{TEM images at room temperature}

The KCoFe-PBA structure has been well investigated by powder X-ray diffraction (PXRD), neutron diffraction and $\mathrm{EXAFS}^{7,8(\mathrm{c}), 9}$ and shown to be a three-dimensional Fe-CN-Co cubic framework with $a=10.3 \AA$ at room temperature. ${ }^{9}$ Figure 2(a)-(c) display TEM images of a $\mathrm{K}_{0.3} \mathrm{Co}\left[\mathrm{Fe}(\mathrm{CN})_{6}\right]_{0.77} \cdot n \mathrm{H}_{2} \mathrm{O}$ particle under different magnifications at room temperature. Fringes associated with the cubic structure are clearly observed by using the ionic liquid [Ch] [Lac]. Figure $2(\mathrm{~d})$ is a $1500 \mathrm{k}$ magnification HRTEM image taken at $286 \mathrm{~K}$, and a coherent shepherd-check pattern related to the alternating cobalt ion and iron ion atomic array is observed. There are also many random blurred regions in the crystal, probably caused by defects associated with $\left[\mathrm{Fe}(\mathrm{CN})_{6}\right]^{3-/ 4-}$ octahedral vacancies. To extract atomic positions, the background of the TEM image is subtracted by first performing a fast Fourier transformation (FFT), Figure 2(e), followed by inverse fast Fourier transformation (IFFT), Figure $2(f)$, to give a weighted image of the lattice structure. Many defects randomly distributed on the crystal plane and an inhomogeneous strain distribution is observed. We calculated the atomic coordinates of the Co and/or Fe atoms under translation symmetry by using the points with brightest intensities, which are on centers of the Co-Fe square lattice in the bright-field images. The Co-Fe distances within the sub-cubic lattice structures are about $\sim 5 \AA$, consistent with the Co-NC-Fe distance of $5.15 \AA$ A determined by X-ray diffraction. ${ }^{9}$

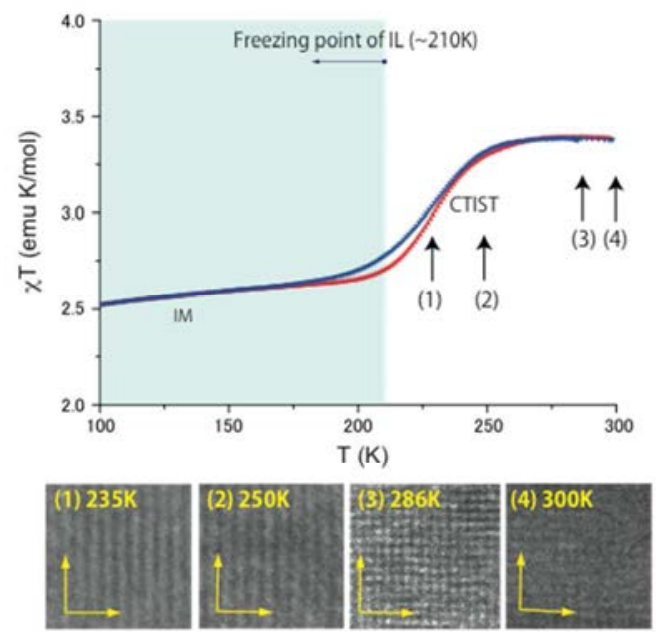

Figure3. Temperature dependence of the magnetic susceptibility for $\mathrm{K}_{0.3} \mathrm{Co}\left[\mathrm{Fe}(\mathrm{CN})_{6}\right]_{0.77} \cdot n \mathrm{H}_{2} \mathrm{O}$, measured while cooling (blue) to generate the IM phase or warming (red) at 1 $\mathrm{K} / \mathrm{min}$. The charge transfer induced spin transition is observed from $\sim 18 \mathrm{oK}$ to $\sim 275 \mathrm{~K}$ on heating. Temperature dependent TEM measurements were performed using ionic liquids during the heating branch from $220 \mathrm{~K}$ to $300 \mathrm{~K}$. $\mathrm{K}_{0.3} \mathrm{Co}\left[\mathrm{Fe}(\mathrm{CN})_{6}\right]_{0.77} \cdot n \mathrm{H}_{2} \mathrm{O}$ is quite sensitive to the electron beam so TEM observations could not be carried out below $\sim 22 \mathrm{~K}$ (light blue region), the freezing point of the ionic liquid.
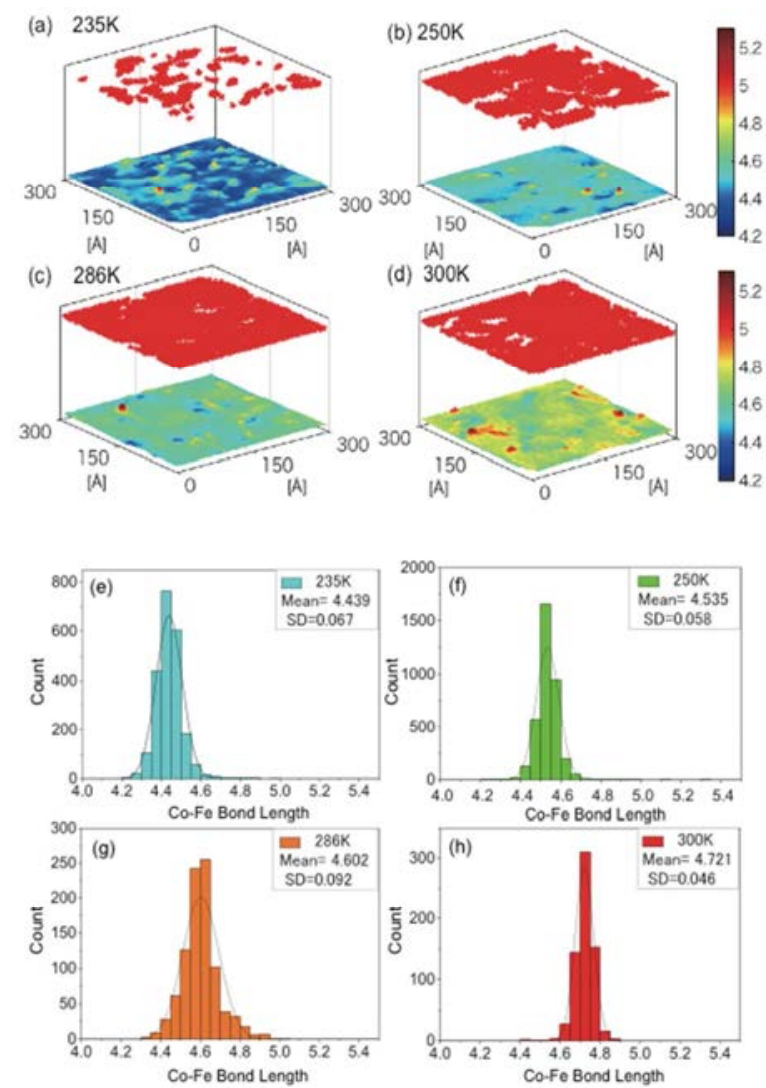

Figure 4. (a) (d) $3 \mathrm{D}$ charts of the Co-Fe distances within approximately $30 \mathrm{~nm} \times 30 \mathrm{~nm}$ crystal planes at several temperatures. The Co-Fe length at each site is measured as the average value between each atom site and its nearest neighbor atoms. The color scale represents the change from LS to HS. Above each map is a $2 \mathrm{D}$ array of red points marking the positions of HS atoms, chosen as those having Co-Fe distances longer than $4.5 \AA$. The number of HS atoms clearly increases with increasing temperature. Plots (e) (h) are the corresponding histograms of Co-Fe lengths obtained from the $3 \mathrm{D}$ charts at several temperatures. Note that the distances are not corrected for TEM calibration and images correspond to different nanoparticles in the same sample batch.

\section{Temperature dependent TEM measurements}

To visualize HS domain nucleation and coarsening during the phase change, temperature dependent TEM measurements were performed on the CTIST heating branch using a liquid He cooled specimen holder. The sample was gradually cooled to about $100 \mathrm{~K}$ to achieve the IM state (Figure 1) and then slowly heated to observe changes as the IM state transitions back to the room temperature HS phase. The sample is easily damaged by the TEM experiment below the freezing point of the ionic liquid $(\sim 210 \mathrm{~K})$ so the study is restricted to temperatures above this point (Figurez).

Figure 4 shows $3 \mathrm{D}$ charts of Co-Fe distances on a $\sim 900 \mathrm{~nm}^{2}$ crystal plane along with histograms of the distribution of Co-Fe distances obtained at several temperatures. Note that the data have not been adjusted for TEM calibration, so measured values have a constant offset of $0.4 \sim 0.5 \AA$ relative to the crystallographically 
determined distances. The color bar gradient spans the distances expected for the LS and HS states and the transition from blue toward red relates to the LS $\rightarrow$ HS conversion. It should be noted that according to magnetic susceptibility data, Figure 3, the low-temperature IM state initially contains about 33\% HS sites, and upon warming to $235 \mathrm{~K}$ about $20 \%$ of the CTIST-active sites have transitioned. The $3 \mathrm{D}$ distribution map of $\mathrm{Co}-\mathrm{Fe}$ distances confirms that the majority is still in the LS state at $235 \mathrm{~K}$, and HS structures with short coherence are randomly distributed in the LS lattice.

The mean (uncorrected) Co-Fe lengths can be obtained from Gaussian fits to the histograms in Figure 4(e)-(f). At $235 \mathrm{~K}$ the mean distance is $4.439 \AA$ with standard deviation (SD) $0.067 \AA$. The mean bond length shifts to $4.535 \AA$ (SD of $0.058 \AA$ ) at $250 \mathrm{~K}$. After applying a constant calibration offset, the mean values are consistent with X-ray diffraction data, which showed $\sim 5.06 \AA$ at $235 \mathrm{~K}$ and $5.13 \AA$ at $250 \mathrm{~K}$ for a sample of $500 \mathrm{~nm}$ particles. ${ }^{9}$ According to the magnetic suscep- tibility measurement the CTIST is complete by $286 \mathrm{~K}$, while the TEM image analysis shows the mean Co-Fe length of $4.602 \AA$ (SD of $0.092 \AA$ ) still approaching the room temperature value of $4.721 \AA$ (SD of $0.046 \AA$ ). The discrepancy is likely a consequence of comparing a single particle to a bulk measurement representing an ensemble of particles.

The imaging of domains gives insight into the mechanism of the elastic phase transition and provides an opportunity to compare its progress to different models for cooperative spin transitions. In systems dominated by short range interactions, transitions are barrier crossing processes requiring a nucleation event, and the key parameters determining the critical size of a nucleus are the interplay between its surface and bulk free energies. The nucleation of the new phase is more favorable at the surface (or around the defects) of the material than in the bulk. The density of nucleation sites is then expected to be larger at particle edges, although as a system becomes larger, nucleation in the bulk may domi- (a)

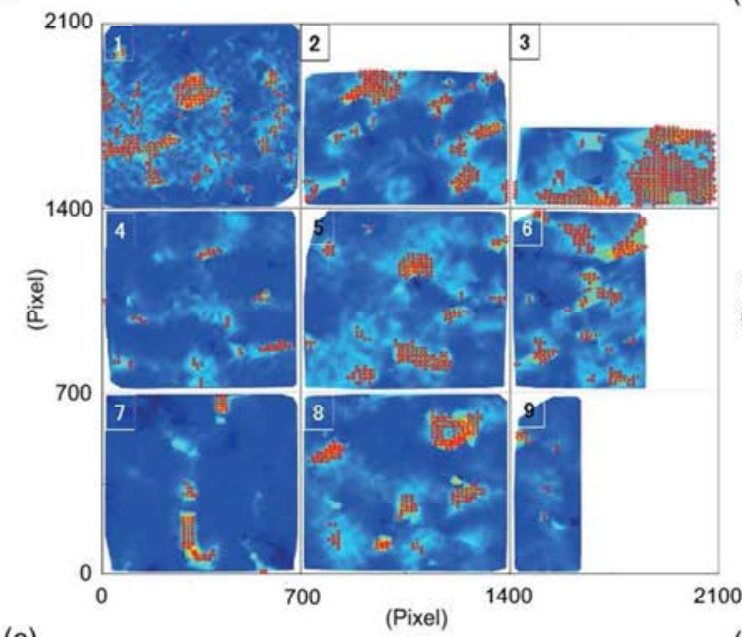

(c)

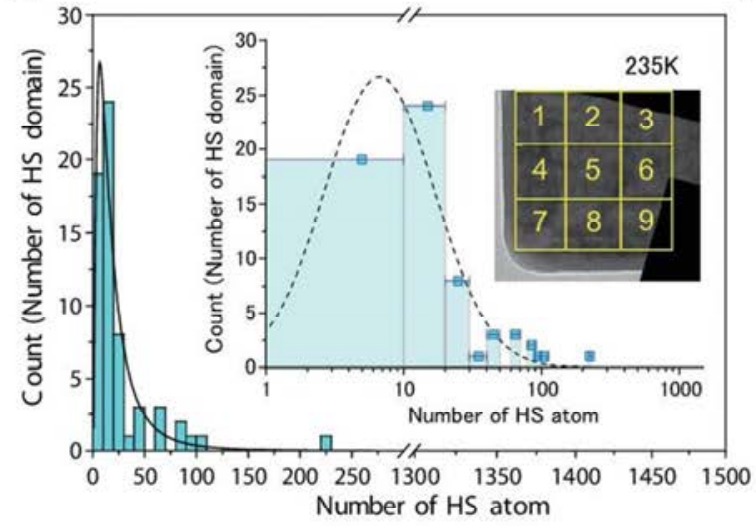

(b)

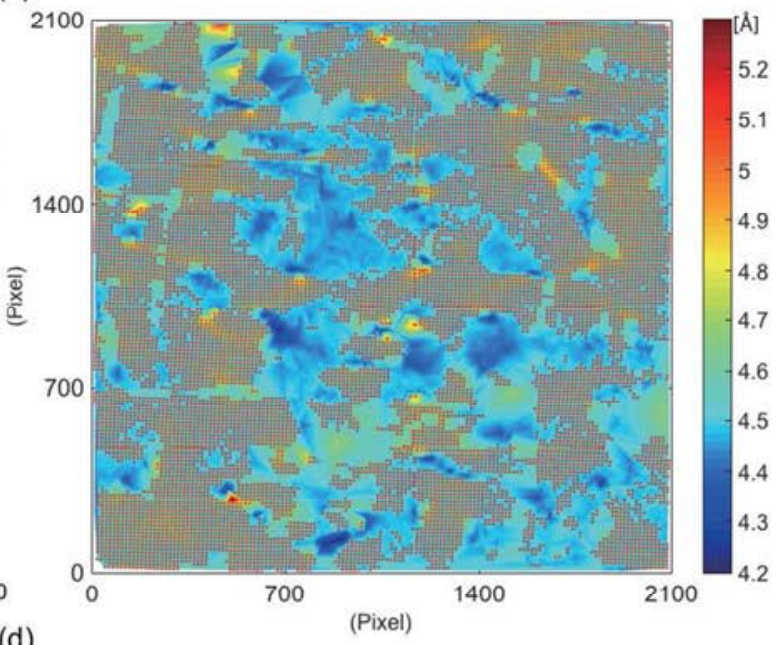

d)

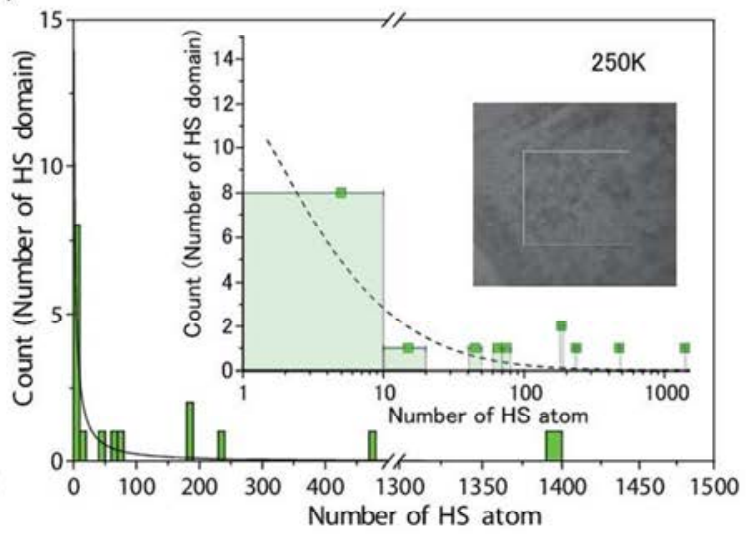

Figure 5. TEM image analysis of a $\sim 2100$ pixel $\times 2100$ pixel (about $65.6 \mathrm{~nm} \times 65.6 \mathrm{~nm}$ ) crystal plane at (a) $235 \mathrm{~K}$ and (b) $250 K$. The images correspond to different nanoparticles in the same sample batch. The color bar represents the average CoFe distances at each site. Co-Fe distances associated with HS atoms ( $>$ > 4.5 $\AA$ ) are indicated with red makers. At $235 \mathrm{~K}$ (image a) the image is divided into nine $700 \times 700$ pixel spatial segments and the local lattice distortion is calculated in each segment. (c) Distribution of the number coherent HS domains of various sizes, plotted according to the number of atoms in a domain, $235 \mathrm{~K}$. The black solid line in (c) is a fit to a log-normal distribution. (inset) the same data plotted on a log scale and the spatial segmentation of the TEM image for (a). (d) Distribution of the number of coherent HS domains of various sizes at $25 \mathrm{oK}$. The black solid lines in (d) fits a log-normal distribution; the insets shows the plot on a log scale along with the TEM image used for the data analysis at $25 \mathrm{oK}$. 
nate. On the other hand, when the spin state changes are accompanied by adjustments in unit cell volume (bond lengths or molecular size), the local volume changes are delocalized over the lattice, causing longrange interactions. ${ }^{17,18}$ For example, a recent model predicts an attractive interaction between two HS atom defects in a LS lattice of as much as $30 \mathrm{meV} .{ }^{18}$

The growth of HS domains in $\mathrm{K}_{0.3} \mathrm{Co}\left[\mathrm{Fe}(\mathrm{CN})_{6}\right]_{0.77} \cdot n \mathrm{H}_{2} \mathrm{O}$ as it is warmed through the CTIST are clearly seen within the bulk of the particles in the TEM images (Figure 4). Sites were defined as in the HS state by a Co-Fe distance longer than $4.5 \AA(L>4.5 \AA)$, since $99.9 \%$ of Co-Fe pairs satisfy this condition at $300 \mathrm{~K}$. The spatial distribution of HS sites is visualized at four temperatures in Figure 4, and over larger regions at $235 \mathrm{~K}$ and $250 \mathrm{~K}$ in Figure 5 for which the total calculated crystal plane size is about 2100 pixels $(65.6 \mathrm{~nm} \times 65.6 \mathrm{~nm})$. In Figure 5(a) and (b), atoms corresponding to the $L>4.5$ $\AA$ criterion are denoted with red marks on the color map. The average size of coherent HS structure at $235 \mathrm{~K}$ from Figure 5(c) is $534.5 \AA^{2}$, containing about $26 \mathrm{Co} / \mathrm{Fe}$ atoms, with the average Co-Fe distance of $4.572 \AA$. When increasing temperature, we observe the growth and coalescence of the HS domains. As a result, at $250 \mathrm{~K}$, the number of small coherent HS structures decreased significantly while the average number of HS sites per domain increased up to $\sim 373$ atoms, with the average size reaching $7744 \AA^{2}$ (Figure $5(d)$ ). Based on the $2 \mathrm{D}$ images in Figure 5, the HS fractions in the plane are estimated as $13 \%$ at $235 \mathrm{~K}, 76 \%$ at $250 \mathrm{~K}$. Although quantitatively slightly different, these values parallel those from magnetic data, which result from the bulk response of the system.

A statistical analysis of the number of atoms in the each HS domain at $235 \mathrm{~K}$ and $250 \mathrm{~K}$ is presented in Figure 5 (c) and (d). The distribution is asymmetric, following a log-normal law at $235 \mathrm{~K}$, characteristic of disordered systems ${ }^{19}$ with aging properties. It can also be seen that the developing HS structures have short coherence length and do not show any clear spatial selforganization. Furthermore, the short coherence-length structures are irregularly-shaped. The $235 \mathrm{~K}$ images indicate that the IM phase is structurally disordered with residual HS domains embedded in a largely LS lattice. The present ramified structure contrasts with recent optical microscopy imaging on spin-crossover solids, and theoretical studies that show phases propagating from a nucleation point as a single domain. ${ }^{20,21}$ From the viewpoint of the elastic process, these small HS domains inside the LS lattice can be considered as Eshelby inclusions with shape and size different from the hosting cavity. ${ }^{22}$ Therefore, a stress field at the interface and inside the domains (for smaller coherent structures) is expected, induced by the lattice parameter misfit between the HS and the LS states. This picture is consistent with the X-ray diffraction analysis, which showed unrelaxed lattice constants for the HS fraction. $^{8 \mathrm{~b}, 10}$

The presence of a large number of irregular domains (Figure $\mathrm{S}_{4}$ ) suggests that there are multiple processes influencing the transition. The stoichiometry of $\mathrm{K}_{0.3} \mathrm{Co}\left[\mathrm{Fe}(\mathrm{CN})_{6}\right]_{0.77} \cdot \mathrm{nH}_{2} \mathrm{O}$ dictates that there are random cyanometallate vacancies in the lattice with $\mathrm{K}^{+}$ions disordered in the interstices. The presence of defects has a profound impact on the mediation of the elastic interactions (the volume change). Vacancies or substitution of cyanide ligands by water molecules favours the HS Co species, ${ }^{23}$ which provide sites of nucleation in the LS $\rightarrow$ HS transition. At the same time, the defects hinder the domain propagation by weakening the elastic interactions. These structural observations for $\mathrm{K}_{0.3} \mathrm{Co}\left[\mathrm{Fe}(\mathrm{CN})_{6}\right]_{0.77} \cdot n \mathrm{H}_{2} \mathrm{O}$ are also consistent with the spin-glass like character of the IM phase, detected using bulk magnetic susceptibility measurements, that often characterizes this family of compounds. ${ }^{8(\mathrm{c}), 24}$

\section{Conclusion}

The use of an ionic liquid has enabled the direct TEM observation of local atomic structure at different temperatures during a solid-solid phase transition in the coordination polymer $\mathrm{K}_{0.3} \mathrm{Co}\left[\mathrm{Fe}(\mathrm{CN})_{6}\right]_{0.77} \cdot n \mathrm{H}_{2} \mathrm{O}$. The ionic liquid prevents the electron beam damage normally encountered during TEM observation of porous coordination polymers or metal organic frameworks and this approach should have profound impact on studies of these classes of materials.

Images evidence the elastic nature of the coordination polymer crystal and the existence of many defects. Nevertheless, the spatial distribution of the Co-Fe distances as the solid undergoes the CTIST was directly measured. At low temperature, a snapshot of the previously identified $\mathrm{K}_{0.3} \mathrm{Co}\left[\mathrm{Fe}(\mathrm{CN})_{6}\right]_{0.77} \cdot n \mathrm{H}_{2} \mathrm{O}$ intermediate (IM) state reveals the existence of small-coherence length HS structures randomly scattered within the LS lattice. As the temperature increases, Co-Fe distances clearly lengthen as the CTIST progresses, allowing a trace of the HS domain growing and coarsening on a nanoscopic scale.

The ability to directly observe crystal elasticity was used here to quantify spatial changes in local elastic properties for a mixture of phases during a phase change, but could be extended to other analyses such as fractal shape of the HS/LS interfaces upon phase transition. Furthermore, it can be expected that direct TEM observation becomes an important analytical technique for understanding local structure during elastic transformations associated with a range of functions of coordination polymer materials, including ion storage, gas sorption and other host-guest processes.

\section{ASSOCIATED CONTENT}

\section{Supporting information}

Magnetization data at $6 \mathrm{~K}$; effects of electron beam dose and stability in ionic liquids; distribution of particle sizes; additional room temperature TEM images.

\section{AUTHOR INFORMATION}

\section{Corresponding Author}

talham@chem.ufl.edu

itoi.miho@nihon-u.ac.jp 


\section{Notes}

The authors declare no competing financial interests.

\section{ACKNOWLEDGMENT}

The authors thank to Prof. Dr. Miyashita, Prof. Dr. C. Enachescu, Dr. I. Maurin, Dr. S. Otake, Dr. K. Tashiro, Dr. Y. Sato, Dr. R. Inoue and Dr. M. Sy for helpful discussion. Two kinds of hydrophobic IL were produced by Prof. K. Tsunashima in National Institute of Technology, Wakayama College. This work was carried out under the Visiting Researcher's Program of the Institute for Solid State Physics, the University of Tokyo. Partial support by the US National Science Foundation via award DMR1405439 (DRT) is gratefully acknowledged. MI would like to thank UVSQ and CNRS for financial support as an invited researcher.

\section{REFERENCES}

(1) (a) Kitagawa, S.; Kitaura, R.; Noro, S.-i. Angew. Chem. Int. Ed. 2004, 43, 2334-2375. (b) Corma, A.; Garcia, H.; Llabres, i.; Xamena, F. X. Chem. Rev. 2o10, 110, 4606-4655. (c) Ohkoshi, S.-i.; Tokoro, H. Acc. Chem. Res. 2012, 45, 1749-1758.

(2) (a) Alamri, H.; Ballot, N.; Long, J.; Guari, Y.; Larionova, J.; Kleinke, K.; Kleinke, H.; Prouzet, E. Chem. Mater. 2014, 26, 875-885. (b) Talham, D. R.; Meisel, M. W. Chem. Soc. Rev. 2011, 40, 3356-3365. (c) Risset, O. N.; Quintero, P. A.; Brinzari, T. V.; Andrus, M. J.; Lufaso, M. W.; Meisel, M. W.; Talham, D. R. J. Am. Chem. Soc. 2014, 136, 15660-15669. (d) Presle, M.; Maurin, I.; Maroun, F.; Cortès, R.; Lu, L.; Hassan, R. S.; Larquet, E.; Guigner, J.; Rivière, E.; Wright, J. P.; Boillot, J, Gacoin, T. J. Phys. Chem. C, 2014, 118, 13186-13195. (e) Catala, L.; Brinzei, D.; Prado, Y.; Gloter, A.; Stephan, O.; Rogez, G.; Mallah, T. Angew. Chem., Int. Ed. 2009, 48, 183-187. (f) Betard, A.; Fischer, R. A. Chem. Rev. 2012, 112, 1055-1083.

(3) (a) Imanishi, N.; Morikawa, T.; Kondo, J.; Yamane, R.; Takeda, Y.; Yamamoto, O.; Sakaebe, H.; Tabuchi, M. J. Power Sources 1999, 81-82, 530-534. (b) Okubo, M.; Asakura, D.; Mizuno, Y.; Kudo, T.; Zhou, H.; Okazawa, A.; Kojima, N.; Ikedo, K.; Mizokawa, T.; Honma, I. Angew. Chem., Int. Ed. 2011, 50, 6269-6273. (c) Asakura, D.; Li, C. H.; Mizuno, Y.; Okubo, M.; Zhou, H.; Talham, D. R. J. Am. Chem. Soc. 2013, 135, 2793-2799. (d) Pasta, M.; Wessells, C. D.; Liu, N.; Nelson, J.; McDowell, M. T.; Huggins, R. A.; Toney, M. F.; Cui, Y. Nat. Commun. 2014, 5, 3007. (e) Wang, L.; Lu, Y.; Liu, J.; Xu, M.; Cheng, J.; Zhang, D.; Goodenough, J. B. Angew. Chem., Int. Ed. 2013, 52, 1964-1967.

(4) (a) Chapman, K. W.; Chupas, P. J.; Kepert, C. J. J. Am. Chem. Soc. 2006, 128, 7009-7114. (b) Goodwin, A. L.; Chapman, K. W.; Kepert, C. J. J. Am. Chem. Soc. 2005, 127, 17980-17981. (c) Adak, S.; Daemen, L. L.; Nakotte, H. J. Phys.: Conf. Ser. 2o1o, 251, 012007 . 6833 .

5) Tokoro, H.; Ohkoshi, S.-i. Dalton Trans. 2011, 40, 6825-

(6) (a) Sato, O.; Iyoda, T.; Fujishima, A.; Hashimoto, K. Science. 1996, 272, 704-705. (b) Sato, O.; Einaga, Y.; Iyoda, T.; Fujishima, A.; Hashimoto, K. J. Electrochem. Soc. 1997, 144, L11L13. (c) Bleuzen, A.; Lomenech, C.; Escax, V.; Villain, F.; Varret, F.; Cartier dit Moulin, C.; Verdaguer, M. J. Am. Chem. Soc., 200o, 122, 6648-6652. (d) Maurin, I.; Chernyshov, D.; Varret, F.; Bleuzen, A.; Tokoro, H.; Hashimoto, K.; Ohkoshi, S. Phys. Rev. B. 2009, 79, 064420.

(7) (a) Cartier dit Moulin, C.; Villain, F.; Bleuzen, A.; Arrio, M.; Sainctavit, P.; Lomenech, C.; Escax, V.; Baudelet, F.; Dartyge, E.; Gallet, J.; Verdaguer, M. J. Am. Chem. Soc. 2ooo, 122, 6653-6658. (b) Yokoyama, T.; Ohta, T.; Sato, O.; Hashimoto, K. Phys. Rev. B. 1998, 58, 8257-8266. (c) Escax, V.; Cham- pion, G.; Arrio, M.; Zacchigna, M.; Cartier dit Moulin, C.; Bleuzen, A. Angew. Chem., Int. Ed. 2005, 44, 4798-4801.

(8) (a) Park, J.-H.; Frye, F.; Anderson, N. E.; Pajerowski, D. M.; Huh, Y. D.; Talham, D. R.; Meisel, M. W. J. Magn. Magn. Mater. 2007, 310, 1458-1459. (b) Chong, C.; Itoi, M.; Boukheddaden, K.; Codjovi, E.; Rotaru, A.; Varret, F.; Frye, F. A.; Talham, D. R.; Maurin, I.; Chernyshov, D.; Castro, M. Phys. Rev. B. 2011, 84 144102. (c) Pajerowski, D. M.; Garlea, V. O.; Knowles, E. S.; Andrus, M. J.; Dumont, M. F.; Calm, Y. M.; Nagler, S. E.; Tong, X.; Talham, D. R.; Meisel, M. W. Phys. Rev. B. 2012, 86, 054431.

(9) Itoi, M.; Maurin, I.; Varret, F.; Frye, F. A.; Talham, D. R.; Chernyshov, D.; Boukheddaden, K. Phys. Rev. B. 2013, 88, 094104.

(10) Andrus, M. J.; Calm, Y. M.; Knowles, E. S.; Dumont, M. F.; Abboud, K. A.; Meisel, M. W.; Talham, D. R. Polyhedron, 2013, 64, 289-293.

(11) (a)Rasband, W. S., ImageJ, U. S. National Institutes of Health, Bethesda, Maryland, USA, http://imagej.nih.gov/ij/, 1997-2014.(b) Schneider, C. A.; Rasband, W. S.; Eliceiri, K. W. Nat. Methods 2012, 9, 671-675. (c) Abramoff, M. D.; Magalhaes, P. J.; Ram, S. J. Biophotonics Int. 2004, 11(7), 36-42.

(12) (a) Hytch, M. J. Scanning Microsc. 1997, 11, 53-66. (b) Diercks, D.; Lian, G.; Chung, J.; Kaufan, M. J. Microsc. 2011, 241 (pt2), 195-199. (c) Hÿtch, M. J.; Snoeck, E.; Kilaas, R. Ultramicroscopy. 1998, 74 131-146. (d) Kundu, P.; Turner, S.; Van Aert, S.; Ravishankar, N.; Tendeloo, G. V. ACS Nano 2014, 8, 599-6o6.

(13) Egerton, R. F.; Malac, P. L. M. Micron 2004, 35, 399-409.

(14) Torimoto, T.; Tsuda, T. ; Okazaki, K. ; Kuwabata, S. Adv. Mater 2010, 22, 1196-1221.

(15) (a) Kuwabata, S.; Kongkanand, A; Oyamatsu, D.; Torimoto, T. Chem. Lett. 2006, 35, 6oo-6o1. (b) Arimoto, S.; Oyamatsu, D.; Torimoto, T.; Kuwabata, S. ChemPhysChem 2008, 9, 763-767. (c) Tsuda, T., Mochizuki, E., Kishida, S., Nemoto, N., Ishigaki, Y., Kuwabata, S. in Molten Salts Chemistry \& Technology, Gaune-Escard, M.; Haarberg, G., Eds.; John Wiley \& Sons: Chichester, UK 2014; pp. 373-389.

(16) Uematsu, T.; Baba, M.; Oshima, Y.; Tsuda, T.; Torimoto, T.; Kuwabata, S. J. Am. Chem. Soc. 2014, 136, 13789-13797.

(17) Miyashita, S.; Konishi, Y.; Nishino, M.; Tokoro, H.; Rikvold, P. A. Phys. Rev. B 2008, 77, 014105.

(18) Slimani, A; Boukheddaden, K.; Varret, F.; Oubouchou, H.; Nishino, M; Miyashita, S. Phys. Rev. B 2013, 87, 01411.

(19) (a) Katsuragi, H.; Sugino, D.; Honjo, H. Phys. Rev. E 2004, 70, 065103. (b) Kadono, T.; Arakawa, M. Phys. Rev. E 2002, 65, 035107.

(20)(a) Slimani, A; Varret, F; Boukheddaden, K.; Garrot, D.; Oubouchou, H.; Kaizaki, S. Phys. Rev. Lett. 2013, 110, 087208. (b) Sy, M.; Varret, F.; Boukheddaden, K.; Bouchez, G.; Marrot, J.; Kawata, S.; Kaizaki, S. Angew. Chem., Int. Ed. 2014, 53, 75397542. (c) Nishino, M; Boukheddaden, K.; Konishi, Y.; Miyashita, S. Phys. Rev. Lett. 2007, 98, 247203. (d) Enachescu, C.; Nishino, M.; Miyashita, S.; Hauser, A.; Stancu, A.; Stoleriu, L. Europhys. Lett. 2010, 91, 27003.

(21) Chong, C.; Mishra, H.; Boukheddaden, K.; Denise, S.;Bouchez, G.; Collet, E.; Ameline, J.; Naik, A. D.; Garcia, Y. Varret, F. J. Phys. Chem. B 2010, 114, 1975-1984.

(22) (a) Seitz, D.; Turnbull, D. Solid state physics : advances in research and applications, vol.3; Accademic Press: New York, 1956. (b) Spiering, H.; Willenbacher, N. J. Phys. C: Solid State Phys. 1988, 21, 1423. (c) Willenbacher, N.; Spiering, H. J. Phys.: Condens. Matter 1989, 1, 10089. (d) Boukheddaden, K. Phys. Rev. B 2013, 88, 134105. (e) Eshelby, J. D. Philos. Trans. R. Soc. London, Ser. A 1951, 244, 87.

(23) Kawamoto, T. ; Asai, Y. ; Abe, S. Phys. Rev. B 1999, 6o, 12990-12993.

(24) Pejaković, D. A.; Manson, J. L.; Miller, J. S.; Epstein, A. J. Phys. Rev. Lett. 200o, 85, 1994-1997. 